\title{
Conditional versus Contingent Fees
}

Winand Emons

04-09

May 2004

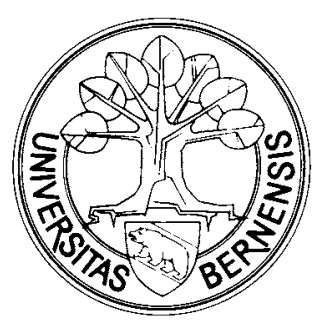

Universität Bern

Volkswirtschaftliches Institut

Gesellschaftstrasse 49

3012 Bern, Switzerland

Tel: 41 (0)31 6314506

Web: www.vwi.unibe.ch 


\title{
Conditional versus Contingent Fees
}

\author{
Winand Emons* \\ University of Bern and CEPR
}

May 2004

\begin{abstract}
Under contingent fees the attorney gets a share of the judgement; under conditional fees the lawyer gets an upscale premium if the case is won which is, however, unrelated to the adjudicated amount. We compare conditional and contingent fees in a framework where lawyers are uninformed about the clients' cases. If there is asymmetric information about the merits of cases, in equilibrium attorneys will offer only conditional fees. If there is asymmetric information about the risk of cases, only contingent fee contracts are offered in equilibrium.
\end{abstract}

Keywords: contingent fees, conditional fees, adverse selection, moral hazard, screening, pooling.

Journal of Economic Literature Classification Numbers: D82, K1.

\footnotetext{
*Universität Bern, Volkswirtschaftliches Institut, Abteilung für Wirtschaftstheorie, Gesellschaftsstrasse 49, CH-3012 Bern, Switzerland, E-mail: winand.emons@vwi.unibe.ch, Homepage: www.vwi.unibe.ch/theory/emons03.htm. I thank Helmut Bester, Nuno Garoupa, Alon Klement, Gerd Mühlheusser, and Zvika Neeman for helpful comments. The hospitality of the department of economics at Purdue University is gratefully acknowledged.
} 


\section{Introduction}

In a typical tort case in the United States the plaintiff's attorney receives his compensation in form of a contingent fee. Under this payment scheme the attorney gets a share of the judgements if his client wins and nothing if his client loses. A common practice is to use a sliding scale: the attorney gets one-third if the case is settled without trial, $40 \%$ if the plaintiff wins at trial, and $50 \%$ if a judgement for the plaintiff is affirmed on appeal.

Contingent fees are the dominant form of payment for plaintiffs' attorneys in personal injury litigation in the United States. According to Kritzer (1990) individual litigants tend to use contingent fees, mostly in torts (87\%) and contracts (53\%); hourly fees are essentially used in divorce and other domestic issues.

In contrast, in Europe contingent legal fees are strictly forbidden: Pactum cuota litis is not allowed by the ethical code of the European association of lawyers. Nevertheless, market pressure has led some countries to allow conditional fees. Under conditional fees the lawyer gets an upscale premium if the case is won. This premium is not related to the adjudicated amount. The United Kingdom started introducing conditional fees in the nineties, followed by Belgium and the Netherlands; the latter is now considering to formally allow contingent fees. Spain, France, Italy, and Portugal are considering the introduction of conditional fees. Germany has also relaxed some restrictions by means of third party contingent contracts, though not to the extreme of accepting conditional fees; see Kirstein and Rickman (2004). ${ }^{1}$

The type of contract for legal fees has been changing rapidly all over Europe, clearly following the US tendency, but still not to the point of allowing contingent fees. Both contingent and conditional fees pay for performance by compensating the lawyer by a higher fee if the case is won. The main difference between contingent and conditional fees is that the former pays a percentage of the judgement whereas the latter pays an upscale premium not related to the adjudicated amount.

\footnotetext{
${ }^{1}$ In class action suits yet another type of contract is used. Under the loadstar fee, contingent on class victory, the attorney receives a fair compensation for the time spent on the case multiplied by a factor reflecting the degree of risk and the quality of work. In contrast to the output-based contingency fees, the loadstar method is input-based; see Klement and Neeman (2004).
} 
Previous literature, which we describe at the end of the Introduction, has mostly addressed the virtues of contingent legal fees, but has ignored the possibility of conditional legal fees. In this paper we compare conditional and contingent fees in a set-up where the client has private information about her case.

We consider two scenarios. In the first scenario clients have cases with different merits. In the second scenario all cases have the same merit but differ in risk. Clients hire an attorney to take their case to court. Attorneys engage in Bertrand competition.

We do not allow for contracts with payments from the attorney to the client. We thus rule out the possibility that the lawyer buys the case from the client and we do not allow for penalties the lawyer has to pay to the client if the case is lost. This restriction follows from the champerty doctrine in the US and the forbidden pactum cuota litis in Europe.

Attorneys strategically choose how much effort they put into a case. Therefore, contracts have to be high-powered to provide incentives for high effort. More precisely, contracts may not entail fixed wages; the lawyer gets nothing when the case is lost. Accordingly, in our setup a contingent fee is simply given by a share of the adjudicated amount the attorney gets when the case is won; a conditional fee is given by a fixed amount for the lawyer if the case is won. Under both contractual forms the lawyer gets nothing if the case is lost.

With asymmetric information about the merits, only a conditional fee contract is offered in equilibrium. This contract induces high effort and lawyers just break even. To see this, suppose that a contingent and a conditional fee contract are offered simultaneously. Then clients with strong cases prefer the conditional fee because they need not share the residual returns. In contrast, clients with weak cases prefer contingency fees because the attorney's share is lower than the conditional fee. If a lawyer offers a contingent fee contract, he only attracts low merit cases; the lawyer thus gets a negative selection of all cases. The expected returns of this contract do not cover the attorney's cost of effort so that he will not offer it in the first place.

With identical merit and asymmetric information about risks, only a contingent fee contract is offered in equilibrium. This contract induces high effort and lawyers just break even. If a contingent and a conditional contract 
are offered simultaneously, high risk clients prefer the conditional fee and low risk clients prefer the contingent fee. To see this note that high risk cases have high stakes but a low probability to prevail. Under conditional fees the lawyer does not participate in the high stakes; he gets a fixed amount if the case is won. The expected returns of the attorney are, however, decreasing in risk. In contrast, under contingent fees the lawyer's expected share is constant and independent of risk. Since the lawyer gets a fraction of the outcome, under contingent fees he is compensated for a low probability to prevail by a high reward if the client wins. Low risk clients prefer contingent fees because for them a share of the outcome is less than the conditional fee that they are very likely to pay. If a lawyer offers a conditional fee contract, he attracts only high risk clients; the lawyer thus gets a negative selection of all cases. The expected returns of this contract do not cover the attorney's cost of effort so that he does better not offer it in the first place.

Our results should become clearer once we draw the analogy between contingent and conditional fees (without fixed wage components) and equity contracts and standard debt contracts (without collateral) to finance risky projects. Our cases are risky projects as are the investment opportunities of entrepreneurs. Entrepreneurs need capital from investors, our clients need effort from lawyers. Capital/effort are lost when the project fails/when the case is lost.

Under equity finance the investor gets a share of the project's returns. So does the attorney under contingent fees. Under a standard debt contract the investor gets a fixed payment (interest plus principle) in non-bankruptcy states and nothing in bankruptcy states. Under conditional fees the attorney gets a fixed premium if the case is won and nothing when the case is lost. Accordingly, contingent and conditional fees generate the same payoff structure as equity and standard debt finance.

Our results are thus related to the literature on adverse selection in credit markets, starting with Stiglitz and Weiss (1981). We derive an extended version of a result by De Meza and Webb (1987): they show that with asymmetric information about returns, investors prefer debt over equity; if there is asymmetric information about risk, investors prefer equity over debt. ${ }^{2}$

\footnotetext{
${ }^{2}$ De Meza and Webb assume pooling. A collateral is not used to screen entrepreneurs. In our model pooling is endogenous. The attorney's choice of effort rules out fixed wage
} 
Let us now briefly summarize the literature. Contingent fees may be seen as a mechanism to finance cases when the plaintiff is liquidity constrained and capital markets are imperfect. Similarly, they may be used by the attorney and her client to share the risk generated by the case efficiently. See, e.g., Posner (1986, 534-540).

Another explanation is related to the use of contingent legal fees in classaction litigation (Lynk, 1990, Klement and Neeman, 2004) and third-party involvement in litigation, such as insurance companies (Kirstein and Rickman, 2004).

The other explanations for contingent fees are all based on asymmetric information between the lawyer and his client. Contingent fees can be used to address a moral hazard problem: If the client cannot observe the attorney's effort, then tying the attorney's fees to the trial's outcome provides better incentives to exert efficient effort than hourly fees which tend to induce shirking (Danzon, 1983; Halpern and Turnbull, 1983; Gravelle and Waterson, 1993; Polinsky and Rubinfeld, 2003; Emons and Garoupa 2004).

Rubinfeld and Scotchmer (1993) suppose that the attorney has better information about his ability and the plaintiff has better information about the merits of her case. A high-quality attorney will signal his ability by working for a high contingency percentage and a low fixed fee. A client who has a high-quality case will be willing to pay a high fixed fee and a low contingency percentage, while a client with a low-quality case will prefer a low fixed fee and a high contingency percentage. In Rubinfeld and Scotchmer a contingency fee contract consists of a fixed wage plus a share of the adjudicated amount. Since contingency contracts are two-dimensional, they obtain separating equilibria. It is rather straightforward to obtain similar separating equilibria with two-dimensional conditional contracts. ${ }^{3}$ In our set-up both types of contracts are one-dimensional which precludes Rubinfeld and Scotchmer type separating equilibria.

Dana and Spier (1993) and Emons (2000) look at the role of the attorney as an expert. Clients do not know the merits of their case. The attorney as

components and thus any possibility to screen clients. Our modelling of mean preserving spreads follows Hellmann and Stiglitz (2000).

${ }^{3} \mathrm{~A}$ conditional contract with a fixed wage corresponds to the standard debt contract with a collateral. If banks choose the collateral and the interest rate, only separating equilibria exist; see Bester (1985). 
the expert finds out about these merits. In Dana and Spier (1993) the lawyer recommends whether to pursue or drop the case; they conclude the optimal compensation scheme will pay the attorney a share of the plaintiff's award. In Emons (2000) the attorney recommends how much work to put into the case; he finds that paying the attorney by the hour is generally better than using contingent fees.

The economic literature on conditional fees is essentially UK-based (Maclean and Rickman, 1999; Yarrow, 2001; Fenn et. al, 2004) and has been concerned with the impact on the outcome of legal cases and the effects on the demand and supply of legal aid.

In Emons and Garoupa (2004) we compare conditional and contingent fees in a principal-agent framework where the lawyer chooses unobservable effort after he has observed the amount at stake. Contingent fees provide better incentives than conditional fees independently of whether upfront payments are restricted to be non-negative or not. Under contingent fees the attorney uses his information about what is at stake more efficiently.

In the next section we describe the model. In section 3 we derive our basic result. Section 4 concludes. Proofs are relegated to the Appendix.

\section{The Model}

We consider a large set of clients each of which has a case. A case may be either lost or won. If the case is lost, the client gets nothing. When the client wins, she gets $J \geq 0$. The probability of prevailing is given as $1 / \sigma, \sigma \geq 1$. Accordingly, a case is a random variable

$$
\tilde{J}= \begin{cases}0, & \text { with }(\sigma-1) / \sigma \\ J, & \text { with } 1 / \sigma\end{cases}
$$

The expected adjudicated amount is $E(\tilde{J}):=\mu=J / \sigma$ and the variance is $\operatorname{Var}(\tilde{J})=\mu^{2}(\sigma-1)$. Accordingly, if $\mu$ is constant, $\sigma$ measures the risk of a case. More precisely, if we hold $\mu$ constant and increase $\sigma$, we have a mean preserving spread; see Rothschild and Stiglitz (1970).

We consider two different sources of asymmetric information. In the first scenario the amount at stake $J \in[0, \infty)$ is known to the client but not to the lawyer. The probability to prevail $1 / \sigma$ is the same for all cases and common knowledge. Asymmetric information with respect to $J$ translates 
into asymmetric information about the expected adjudicated amount $\mu \in$ $[0, \infty)$ which is distributed with c.d.f. $F(\mu)$. Therefore, we will talk about asymmetric information about $\mu$ and call it scenario $\mu$ ).

In scenario $\sigma$ ) all cases have the same expected adjudicated amount $\mu$ which is common knowledge. Here the risk $\sigma \in[1, \infty)$ is distributed with c.d.f. $G(\sigma)$. The realization of $\sigma$ is known to the client but not to the lawyer. Accordingly, only the client knows whether she has a case with a low $J$ and high probability to prevail (a low risk case) or a case where $J$ is high and $1 / \sigma$ low (a high risk case).

To take a case to court a client needs a lawyer. There are at least two risk neutral lawyers with unlimited capacity. Lawyers engage in Bertrand competition which we will make more precise below.

Attorneys either provide zero effort or high effort $e>0$. With zero effort the probability to prevail is zero. With high effort $e$ the probability to win equals $1 / \sigma$ as described above. Effort is not observed by the client. Lawyers only incur the cost of effort which, for simplicity, equals the level of effort $\{0, e\}$. When the lawyer is indifferent as to the choice of effort, he goes for high effort. In scenario $\sigma$ ) let $\mu \geq e$ so that all cases should be taken to court. In scenario $\mu$ ) only those cases with $\mu \geq e$ should be prosecuted.

By giving lawyers the zero effort option, we effectively rule out contracts entailing fixed wages. To see this, first note that we do not allow for contracts with payments from the attorney to the client. We thus rule out the possibility that the lawyer buys the case from the client and we do not allow for penalties the lawyer has to pay to the client if the case is lost. This restriction is implied by the champerty doctrine in the US and the forbidden pactum cuota litis in Europe.

Therefore, in our set-up conditional fees can pay the lawyer a fixed wage plus a fixed extra if the case is won; contingent fees can give the attorney a fixed wage plus a share of the adjudicated amount. Now suppose that under either fee structure the fixed wage is positive. Then the lawyer can ensure himself a positive payoff: he provides zero effort and cashes in on the fixed wage. Due to Bertrand competition this can, however, not happen in equilibrium: any positive payoff will be competed away. As we will see later in equilibrium lawyers offer contracts the returns of which just cover their effort $\operatorname{cost} e$. 
Accordingly, given that we can rule out any fixed wage components, a conditional fee contract is given by

$$
\begin{cases}d, & \text { if the case is won; } \\ 0, & \text { if the case is lost; }\end{cases}
$$

with $d \geq 0$. A contingent fee contract is given by

$$
\begin{cases}\alpha J, & \text { if the case is won; } \\ 0, & \text { if the case is lost; }\end{cases}
$$

with $\alpha \in[0,1]$. In what follows we will identify a conditional fee contract by $d$ and a contingent fee contract by $\alpha$.

Under the conditional fee contract $d$ with high lawyer effort $e$ the client's expected utility is

$$
U(d)=\frac{1}{\sigma}(J-d)=\mu-\frac{d}{\sigma}
$$

and the lawyer's expected utility per client (the expected return per client) amounts to

$$
V(d)=\frac{d}{\sigma}-e
$$

If the lawyer picks zero effort, $U(d)=V(d)=0$.

Under the contingent fee contract $\alpha$ with high lawyer effort $e$ the client's expected utility is

$$
U(\alpha)=(1-\alpha) \mu
$$

and the lawyer's expected utility per client amounts to

$$
V(\alpha)=\alpha \mu-e
$$

With zero effort, $U(\alpha)=V(\alpha)=0$. Client and lawyer participate as long as $U, V \geq 0$.

The sequencing of events is as follows. In the first stage each lawyer offers one contract: either a conditional fee $d \geq 0$ or a contingent fee contract $\alpha \in[0,1]$. In the second stage each client chooses either one contract on offer or no contract at all. In the third stage attorneys form their beliefs about the $\mu(\sigma)$ of their clientele and pick their effort. Clients maximize the expected difference between abjudicated amount and payments to the lawyer. Attorneys maximize their expected wages minus effort cost. 
We focus on symmetric perfect Bayesian equilibria of this screening game. ${ }^{4}$ Note that both types of contracts are one dimensional. Accordingly, it is not possible for lawyers to screen clients with contingent contracts alone (conditional contracts alone). We can thus expect some pooling in equilibrium. Nevertheless, there is the possibility that in equilibrium a contingent and a conditional contract are offered simultaneously, each of which attracts a different set of clients.

\section{Equilibria}

Let us now describe equilibrium behavior of our game. It turns out that the equilibria have a neat structure. In scenario $\mu$ ) all attorneys offer a conditional fee and no contingent fee contract. Attorneys provide high effort under the conditional fee and just break even. Client's whose $\mu$ exceeds the effort cost $e$ buy the contract. In scenario $\sigma$ ) all attorneys offer a contingent fee and no conditional fee contract. Attorneys provide high effort under the contingent fee and make zero-profits. All clients buy the contract.

Proposition 1: With asymmetric information about $\mu$, there exists an equilibrium where all attorneys offer the conditional fee contract $d^{*}=e \sigma$ and no contingent fee contract. All clients with $\mu \geq e$ buy the contract. Lawyers correctly expect $E(\mu)=\int_{e}^{\infty} \mu d F(\mu)$ and choose high effort.

With asymmetric information about $\sigma$, there exists an equilibrium where all attorneys offer the contingent fee contract $\alpha^{*}=e / \mu$ and no conditional fee contract. All clients buy the contract. Lawyers correctly expect $E(\sigma)=$ $\int_{1}^{\infty} \sigma d G(\sigma)$ and choose high effort.

The intuition for the first result is as follows. Suppose a contingent fee $d$ and a conditional fee contract $\alpha$ are offered simultaneously. Then those clients whose $\mu$ is above $d / \alpha \sigma$ prefer the conditional fee while those clients with $\mu$ below $d / \alpha \sigma$ go for the contingent contract.

The reason for this self-selection of clients is that clients with strong cases (high $\mu$ ) prefer the conditional fee because they need not share the residual returns. The payment to the attorney is fixed at $d$ and the client keeps the

\footnotetext{
${ }^{4}$ In a screening game the uninformed party moves first; in a signaling game the informed party moves first.
} 
high $J-d$, which is better than giving the lawyer $\alpha J$. In contrast, clients with weak cases (low $\mu$ ) prefer contingency fees because the attorney's share $\alpha J$ is lower than the conditional fee $d$.

Given this self-selection of clients, suppose now $d^{*}$ is offered on the market. Suppose a lawyer offers a contingent fee contract $\alpha$. Then this contract only attracts clients with low $\mu$; the lawyer thus gets a negative selection of all cases. The expected returns of this contract do not cover the attorney's cost of effort so that he will not offer it in the first place.

The second result rests on the following reasoning. Suppose again a contingent fee $d$ and a conditional fee contract $\alpha$ are simultaneously on the market. Then high risk clients with $\sigma$ above $d / \alpha \mu$ prefer the conditional contract while low risk clients with $\sigma$ below $d / \alpha \mu$ go for the contingent contract.

Here high risk clients prefer the conditional fee because the expected payment to the attorney is decreasing in $\sigma$ : the lower the probability to prevail $1 / \sigma$, the lower the lawyer's expected fee $d / \sigma$. If the case is won under conditional fees, the lawyer doesn't participate in the high $J$; he just gets his fixed conditional fee $d$. The lawyer does, however, participate in the low probability to prevail. In contrast, under contingent fees, the lawyer's expected share $\alpha \mu$ is independent of $\sigma$. Since the lawyer gets a fraction of the outcome, under contingent fees he is compensated for a low probability to prevail by a high share in case the client wins. Low risk clients prefer contingent fees because for them $\alpha \mu$ is less than $d / \sigma$.

With this self-selection of clients, let $\alpha^{*}$ be offered on the market. Suppose a lawyer offers a conditional fee contract $d$. Then this contract only attracts high risk clients; the lawyer thus gets a negative selection of all cases. The expected returns of this contract do not cover the attorney's cost of effort so that he does better not offer it in the first place.

We thus find that in both scenarios only one type of contract is offered in equilibrium: with uncertainty about $\mu$ we observe only conditional fee contracts; with uncertainty about $\sigma$ only contingent fee contracts will be offered.

By giving lawyers the zero effort option, we rule out fixed wages which, in turn, makes both types of contracts one dimensional. Therefore, it is not possible to screen clients with just one of two types of contracts as is the case in Rubinfeld and Scotchmer (1993). We thus impose some pooling. Yet, as 
we have seen in the preceding paragraphs, it is still possible to have some separation of clients if a contingent and a conditional contract are on the market at the same time. Nevertheless, this does not happen in equilibrium. In both scenarios only one contract is offered in equilibrium and no separation takes place.

Note, however, that although clients are lumped together, our pooling equilibria are efficient. Only those clients with cases worthwhile to be taken to court hire an attorney. Moreover, even though our equilibria are of the pooling type, clients with good cases do not subsidize clients with bad cases. In scenario $\mu$ ) all clients pay the same expected amount $d^{*} / \sigma=e$; in scenario $\sigma)$ they all pay $\alpha^{*} \mu=e$.

\section{Conclusions}

In this paper we have compared conditional and contingent fees in a framework where lawyers are not informed about the clients' cases. If there is asymmetric information about the merits of cases, in equilibrium we will only observe conditional fees. If there is asymmetric information about the risk of cases, only contingent fee contracts are offered in equilibrium. These findings are related to similar results in the literature on adverse selection in credit markets. Contingent and conditional fees give rise to the same payoff structure as do equity finance and a standard debt contract.

In the US contingent fees are widely used, in particular by small law firms. In contrast, many large law firms in the US do operate on the basis of a flat fee plus a bonus for performance, i.e., conditional fees, rather than contingent fees (Kritzer, 1990). Accordingly, contingent and conditional fees co-exist in the US, as do equity and debt finance in credit markets. Our model's explanation of this co-existence is that for small law firms risk is the major source of asymmetric information whereas for large law firms the merits of cases are uncertain. It will be interesting to observe what will happen in the Netherlands, where in the future both types of contracts may be allowed for: will conditional fees be substituted by contingent fees or will both contractual forms be used at the same time? 


\section{Appendix}

\section{Proof of Proposition 1:}

Scenario $\mu$ ): To solve the game, let us start with the attorneys' effort choice in stage 3. Denote a lawyer's expectation about the $\mu$ of his clientele by $E(\mu)$. Under the contingent fee $\alpha$ he chooses positive effort if $\alpha E(\mu) \geq e$; under the conditional fee $d$ he picks high effort if $d / \sigma \geq e$.

Let us now turn to the second stage. Let there be one type of conditional fee contract $d$ and one type of contingent fee contract $\alpha$ on the market. If $\alpha<e / E(\mu)$ consumers do not buy the contingent contract $\alpha$ because the attorney will go for zero effort in stage 3. Similarly, if $d<e / \sigma$ consumers do not buy the conditional contract $d$.

Next consider the case where $\alpha<e / E(\mu)$ and $d \geq e / \sigma$. Then $\alpha$ has no customers and clients with $\mu \geq d / \sigma$ buy $d$. If $\alpha \geq e / E(\mu)$ and $d<e / \sigma, d$ has no customers. All clients buy $\alpha$ so that $E(\mu)=\int_{0}^{\infty} \mu d F(\mu)$.

Consider now the case $\alpha \geq e / E(\mu)$ and $d \geq e / \sigma$ so that both contracts induce high effort in stage 3 . Then clients with $\mu \geq d / \alpha \sigma$ prefer the conditional contract $d$ and clients with $\mu<d / \alpha \sigma$ prefer the contingent fee contract $\alpha$. To see this note that $U(d)=\mu-d / \sigma \geq U(\alpha)=(1-\alpha) \mu \Leftrightarrow \mu \geq d / \alpha \sigma$. Moreover, $U(d) \geq 0 \forall \mu \geq d / \alpha \sigma$. For the contingent contract $\alpha, E(\mu)=\int_{0}^{d / \alpha \sigma} \mu d F(\mu)$.

Let us no turn to the first stage. All attorneys will offer the conditional fee contract $d^{*}=e \sigma$. To see this first note that the return per client under high effort $e$ is $V\left(d^{*}\right)=d^{*} / \sigma-e=0$ so that the lawyer provides high effort.

If an attorney unilaterally deviates to $d>d^{*}$, he will lose all his customers. If he deviates to $d<d^{*}$, he loses all clients because this deviation induces zero effort. Accordingly, a deviation to another conditional fee contract is not profitable.

Next suppose an attorney deviates to a contingent fee $\alpha$. If the contingent fee contract induces zero effort, it will not attract clients. Therefore, suppose the contingent fee implements high effort $e$. Then we know from our analysis of stage 2 that all customers with $\mu<d / \alpha \sigma$ prefer the contingent fee $\alpha$, i.e., $U(\alpha)=(1-\alpha) \mu>\mu-d^{*} / \sigma=U\left(d^{*}\right)$. But this implies $\alpha \mu<d^{*} / \sigma=e$, so that the lawyer will not pick high effort. Consequently, a deviation to a contingent fee contract is not profitable.

Scenario $\sigma)$ : Consider the attorneys' effort choice in stage 3. Denote the attorney's

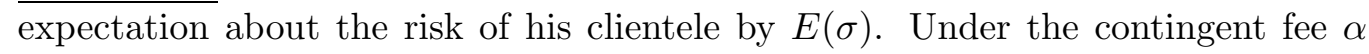
he picks positive effort if $\alpha \mu \geq e$; under the conditional fee $d$ effort is positive if $d / E(\sigma) \geq 0$.

Consider now the second stage. Let there be one type of conditional fee contract $d$ and one type of contingent fee contract $\alpha$ on the market. If $\alpha<e / \mu$ consumers 
do not buy the contingent contract $\alpha$ because the attorney will go for zero effort in stage 3. Similarly, if $d<e / E(\sigma)$ consumers do not buy the conditional contract $d$.

Now take $\alpha<e / \mu$ and $d \geq e / E(\sigma)$. $\alpha$ has no customers. All clients with $\mu \geq$ $d / E(\sigma)$ buy $d$ which is either everybody or nobody. If $\alpha \geq e / \mu$ and $d<e / E(\sigma)$, $d$ has no customers and everybody buys $\alpha$.

Consider now the case $\alpha \geq e / \mu$ and $d \geq e / E(\sigma)$ so that both contracts induce high effort in stage 3. Clients with $\sigma \geq d / \alpha \mu$ prefer the conditional contract $d$ and clients with $\sigma<d / \alpha \mu$ prefer the contingent fee contract $\alpha$. This follows since $U(d) \geq U(\alpha) \Leftrightarrow \sigma \geq d / \alpha \mu$. Furthermore, $U(d) \geq 0 \forall \sigma \geq d / \alpha \mu$. For the conditional contract $d, E(\sigma)=\int_{d / \alpha \mu}^{\infty} \sigma d G(\sigma)$.

Let us no turn to the first stage. All attorneys will offer the contingent fee contract $\alpha^{*}=e / \mu$. With this contract the return per client under high effort $e$ is $V\left(\alpha^{*}\right)=\alpha^{*} \mu-e=0$ so that the lawyer goes for high effort.

If an attorney unilaterally deviates to $\alpha>\alpha^{*}$, he loses all his customers. If he deviates to $\alpha<\alpha^{*}$, he loses all clients because this deviation induces zero effort. Accordingly, a deviation to another contingent fee contract is not profitable.

Next suppose an attorney deviates to a conditional fee $d$. If the contingent fee contract induces zero effort, it will not attract clients. Therefore, suppose the conditional fee implements high effort $e$. Then we know from our analysis of stage 2 that all customers with $\sigma>d / \alpha \mu$ prefer the conditional fee $d$, i.e., $U\left(\alpha^{*}\right)=\left(1-\alpha^{*}\right) \mu<\mu-d / \sigma=U(d)$. But this implies $d / \sigma<\alpha^{*} \mu=e$, so that the lawyer will not pick high effort. Consequently, a deviation to a conditional fee contract is not profitable.

Q.E.D. 


\section{References}

Bester, H. Screening versus Rationing in Credit Markets with Imperfect Information, American Economic Review 75 (1985): 850-855.

Dana, J. And K. Spier. Expertise and Contingent Fees: the Role of Asymmetric Information in Attorney Compensation, Journal of Law, Economics and Organization 9 (1993): 349-367.

Danzon, P. Contingent Fees for Personal Injury Litigation, Bell Journal of Economics 14 (1983): 213-224.

De MezA, D. And D. WebB. Too much Investment: A Problem of Asymmetric Information, Quarterly Journal of Economics 102 (1987): 281-292.

Emons, W. Expertise, Contingent Fees, and Insufficient Attorney Effort, International Review of Law and Economics 20 (2000): 21-33.

Emons, W. And N. Garoupa. The Economics of US-style Contingent Fees and UK-style Conditional Fees, discussion paper 04.07, University of Bern (2004). http://www-vwi.unibe.ch/theory/papers/emons/contfee.pdf

Fenn, P., A. Gray, N. Rickman, and H. Carrier. The Impact of Conditional Fees on the Outcome of Personal Injury Cases, Journal of Insurance Research and Practice (2004): Forthcoming.

Gravelle, H. and M. Waterson. No Win, No Fee: Some Economics of Contingent Legal Fees, Economic Journal 420 (1993): 1205-1220.

Halpern, P. J. and S. M. Turnbull. Legal Fees Contracts and Alternative Cost Rules: An Economic Analysis, International Review of Law and Economics 3 (1983): 3-26.

Hellmann T. And J. Stiglitz. Credit and Equity Rationing in Markets with Adverse Selection, European Economic Review 44 (2000): 281-304.

Klement, A. And Z. Neeman. Incentive Structures for Class Action Lawyers, Journal of Law, Economics, and Organization (2004): 125-147.

Kirstein, R. And N. Rickman. Third Party Contingency Contracts in Settlements and Litigation, Journal of Institutional and Theoretical Economics (2004): forthcoming.

KrItzer, H. The Justice Broker: Lawyers and Ordinary Litigation, Oxford: Oxford University Press (1990).

Lynk, W. J. The Courts and the Market: An Economic Analysis of Contingent Fees in Class-Action Litigation, Journal of Legal Studies 19 (1990): 247-260.

Maclean, M. and N. Rickman. No House, No Fee: Conditional Fees in Family Cases, Family Law 29 (1999): 245-248. 
Polinsky, A. M. And D. Rubinfeld. Aligning the Interests of Lawyers and Clients, American Law and Economics Review 5 (2003): 165-188.

Posner, R. Economic Analysis of Law, 3rd ed., Boston: Little Brown (1986).

Rickman, N. The Economics of Contingency Fees in Personal Injury Litigation, Oxford Review of Economic Policy 10(1994): 34-50.

Rickman, N. Contingent Fees and Litigation Settlement, International Review of Law and Economics 19 (1999): 295-31.

Rothschild, M. AND J. Stiglitz. Increasing Risk I: A definition, Journal of Economic Theory 2 (1970): 225-243.

Rubinfeld, D. And S. Scotchmer. Contingent Fees for Attorneys: An Economic Analysis, Rand Journal of Economics 24 (1993): 343-356.

Stiglitz, J. And A. Weiss Credit Rationing in Markets with Imperfect Information, American Economic Review 71 (1981): 393-410.

Yarrow, S. Conditional Fees, Hume Papers on Public Policy 8 (2001): $1-10$. 